\title{
Insight to Case Reports
}

\section{Ender Hur*}

Zonguldak Karaelmas University Nephrology Department, Zonguldak, Turkey

Historically the case report in medical scientific literature can be traced back to Sydenham in the $17^{\text {th }}$ century; most recently this class of publication is frequently relegated to the realm of anecdotism. This is not necessarily surprising as the account of a single patient in the areas of the determination of accurate screening tests or in the evaluation of treatment efficacy does not provide a predictive value or deal with chance occurrence [1]. But on the other side, the evaluation of a single case can define a novel human disease and raise important hypotheses on causation and pathogenesis. Moreover a publication of case reports provides a rich opportunity for students, residents, and fellows in training who have an interest in pursuing a career in academic medicine.

\section{Case reports in the advancement of scientific knowledge}

1. Case Report: Selected Report

2. Short Reports: Brief Communication

3. Brief Report: Experience Reason

4. Clinical/Scientific Note: Clinical Laboratory

5. Clinical Report: Observations

\section{A case report must define [2]}

Totally original condition/new disease

Rare and previously sparsely reported condition

Unusual presentation of a common illness

Unexpected association between two relatively uncommon symptoms and signs

Impact of one disease process on another

Unexpected event in the course of observing or treating a patient

Impact of a treatment regime of one condition on another disease

Unexpected complication of treatment or procedure

New and unique treatment

Honest mistakes in management

\section{Layout and contents of the case report}

Theme of Educational Message:

Raise awareness so that diagnosis may be made more readily in the future

Shed new light on possible etiology and pathogenesis of a condition or complication

Illustrate a new principle, or support or refute current theory

Elucidate a previously misunderstood clinical condition or response to a treatment

Inform on how a problem can be anticipated and avoided in the future

\section{Abstract}

Clinical question or problem
Summary statement of why this case is noteworthy.

What is the Educational Message?

Can be done away with altogether if the Abstract is satisfactory

\section{Introduction}

Why is this case report important? Why is it being reported?

Put clinical case in context in terms of commonness and seriousness of symptoms, signs of disease; and relevance to the clinical practice of the Target Audience

State: "Reminder of useful findings", "Support another 'unique/ unexpected' case report", "Disagree/Contest another report", etc

\section{Case Description}

\section{Discussion and comments:}

"This case is striking because ......"

Emphasize contentious points. Explain clarify them

"What lessons can be learnt from our experience?":

Implications for prognosis and outcome, and how these are changed in the light of ....

\section{Conclusions/Summary/Recommendations}

'Take-home message' of the lessons learnt

Recommendations for patient management

Interesting lines of research that could be addressed" [3]

Recently there is a trend in decreasing published articles of case reports compared to more analytical work. It is important to know the collected findings from case reports may provide the bases for future researches that will lead to evidence-based treatment. Therefore, it is imperative these cases are reported in the highest possible standard and with great enthusiasm.

\section{References}

1. Carey JC (2006) Significance of case reports in the advancement of medical scientific knowledge. Am J Med Genet A 140: 2131-2134.

2. McCarthy LH, Reilly KE (2000) How to write a case report. Fam Med. 32: 190 195

3. Chelvarajah R, Bycroft J (2004) Writing and publishing case reports: the road to success. Acta Neurochir (Wien) 146: 313-316; discussion 316.

*Corresponding author: Dr. Ender Hur, Zonguldak Karaelmas University Nephrology Department, Zonguldak, Turkey, E-mail: hurender@hotmail.com

Received December 02, 2011; Accepted December 05, 2011; Published December 14, 2011

Citation: Hur E (2011) Insight to Case Reports. J Clinic Case Reports 1:e104 doi:10.4172/2165-7920.1000e104

Copyright: (C) 2011 Hur E. This is an open-access article distributed under the terms of the Creative Commons Attribution License, which permits unrestricted use, distribution, and reproduction in any medium, provided the original author and source are credited. 